\title{
LAW'S ABILITY TO FURTHER THE “MENSTRUAL MOVEMENT"
}

\section{CHRISTOPHER A. COTROPIA*}

\section{INTRODUCTION}

The current menstrual movement ${ }^{1}$ calls for overcoming the cultural stigma associated with menstruation, achieving "menstrual equity," and ending "period poverty." stigma the movement seeks to address is that menstruation is seen as taboo, unclean, and impure. ${ }^{4}$ The movement's aims are twofold: First, it wants to increase awareness of menstruation and remove discrimination against those who menstruate, thus achieving menstrual equity. Second, it intends to provide greater access to menstrual hygiene products ("MHPs"), particularly for homeless and lower income people, thus eliminating period poverty. ${ }^{5}$ To achieve these goals, the movement is advocating to legislatively eliminate the "tampon tax" and increase access to MHPs in prisons, homeless shelters, and schools. ${ }^{7}$ It also supports lawsuits challenging the constitutionality of the tampon tax.

\footnotetext{
* Dennis I. Belcher Professor of Law, University of Richmond School of Law. The author would like to thank Mary Catherine Talbott for her excellent research and editing assistance and the wonderful editorial staff at the Columbia Journal of Gender and Law for making this essay better.
}

${ }^{1}$ See Nadya Okamoto, Period Power: A Manifesto for the Menstrual Movement 10-12 (2018) (“The Menstrual Movement is the fight for equitable access to period products and the fight to break down the stigma around periods. ... It is up to us to start conversations and change the narrative around periods so turn to your neighbor and ask, 'Why are we so afraid to talk about something so natural?'”).

${ }^{2}$ See Jennifer Weiss-Wolf, Period Gone Public: Taking a Stand for Menstrual Equity 1-7 (2017).

${ }^{3}$ See Anne Sebert Kuhlmann, Eleanor Peters Bergquist, Djenie Danjoint \& L. Lewis Wall, Unmet Menstrual Hygiene Needs Among Low-Income Women, 133 OBstetrics \& GyNeCOLOGy 238, 238-39 (2019).

${ }^{4}$ Elissa Stein \& Susan Kim, Flow: The Cultural Story Of Menstruation 117-18 (2009); see also Katherine Allen, Christine Kaestle \& Abbie Goldberg, More Than Just a Punctuation Mark: How Boys and Young Men Learn about Menstruation, 32 J. FAM. Issues 129, 133, 152 (2011).

${ }^{5}$ See Kuhlmann et al., supra note 3, at 239.

${ }^{6}$ See Bridget J. Crawford \& Carla Spivack, Tampon Taxes, Discrimination, and Human Rights, 491 WISC. L. REv. 512, 512-27 (2017).

${ }^{7}$ See Margaret E. Johnson, Emily Gold Waldman \& Bridget J. Crawford, Title IX \& Menstruation, 43 Harv. J. L. \& GENDER 225, 227-228 (2020). 
Advocates view these legal changes as instrumental in furthering the goals of equity and access to MHPs that underlie the movement. This Essay discusses whether the two major legislative changes the movement advocates - repeal of the tampon tax and providing MHPs in schools for free-will actually achieve the movement's goals. The Essay begins by explaining how these legal changes, in theory, are meant to address menstrual equity and period poverty. It then explores the operational limits to, and expressive benefits of, these legal proposals. The Essay concludes that the expressive function of demanding these legal changes, and sometimes achieving them, plays a more significant role than the laws' actual operation in reaching the movement's goals.

\section{Two Proposed Legal Changes to Achieve Menstrual Equity and Eliminate Period Poverty ${ }^{8}$}

\section{A. Eliminating the "Tampon Tax"}

One call for legal change is the elimination of the sales tax imposed on MHPs. The menstrual movement has prompted twenty-plus states to consider legislation to exclude MHPs from the sales tax, with seventeen states passing such legislation and removing the tax. ${ }^{9}$ The movement has also pursued litigation to force removal of the tax on equal protection grounds in cases filed in New York ${ }^{10}$ and Michigan. ${ }^{11}$

Taxing MHPs is viewed as unfair and inequitable because MHPs are necessities. ${ }^{12}$ Their taxation is especially inequitable given that it targets an "immutable" characteristic of roughly half the population. ${ }^{13}$ This tampon tax is seen as a de facto tax on being a

\footnotetext{
${ }^{8}$ There are other access changes advocated for by the movement such as requiring free MHPs in prisons and homeless shelters. See, e.g., Margaret E. Johnson, Menstrual Justice, 53 U.C. DAVIS L. REV. 1, 47-48 n. 329 (collecting state legislation). While not discussed in this essay, the essay's analysis of MHPs in school legislation is also applicable to these targeted, MHP access laws.

${ }^{9}$ See, e.g., Bridget J. Crawford \& Emily Gold Waldman, The Unconstitutional Tampon Tax, 53 U. Rich. L. REV. 439, 449-456 (2019) (including California, Connecticut, District of Columbia, Florida, Illinois, Maryland, Massachusetts, Minnesota, Nevada, New Jersey, New York, Ohio, Pennsylvania, Rhode Island, Utah, Virginia, and Washington).

${ }^{10}$ Compl., Siebert v. N.Y. St. Dep’t of Tax. \& Finance, No. 151800/2016 (N.Y. Sup. Ct. Mar. 3, 2016).

${ }^{11}$ Beggs v. State of Mi. \& Mi. Dep’t. of Treasury, No. 20-000149-MT (M.I. Ct. Cls. Aug. 11, 2020).

${ }^{12}$ See, e.g., Crawford \& Spivack, supra note 6, at 512-27.

${ }^{13}$ Jorene Ooi, Bleeding Women Dry: Tampon Taxes and Menstrual Inequity, 113 Nw. UNIV. L. REv. 109, 130-137 (2018).
} 
woman. ${ }^{14}$ This inequity is amplified because many products that are used to treat biologically male-oriented conditions are exempt from sales taxes.

Repealing tampon taxes can also increase MHP affordability and, in turn, accessibility by lowering consumer prices. ${ }^{15}$ MHPs are expensive products and few, if any, public assistance programs cover MHPs.${ }^{16}$ Lowering the price by removing the tax helps address period poverty.

\section{B. Providing Free MHPs in Schools}

Another legislative push would require public and middle schools to provide MHPs in bathrooms at no charge. ${ }^{17}$ So far, over twenty-five states have considered such legislation, and it has passed in seven states: California, Georgia, Illinois, Tennessee, New York, New Hampshire, and Virginia. ${ }^{18}$

Legislation requiring the provision of MHPs in schools is based in part on the desire for menstrual equity. Menstrual management, particularly for school-aged individuals, is an important public health and educational issue. ${ }^{19}$ Providing MHPs in school restrooms for free can address the stigma associated with needing to ask for assistance —often from a male teacher or administrator, improve attendance and performance in school, and support health in general. ${ }^{20}$ The provision of MHPs, no questions asked, in the privacy of

\footnotetext{
${ }^{14}$ See, e.g., Victoria Hartman, End the Bloody Taxation: Seeing Red on the Unconstitutional Tax on Tampons, 112 Nw. U. L. ReV. 313, 316-320 (2017).

${ }^{15}$ See Christopher A. Cotropia \& Kyle Rozema, Who Benefits from Repealing Tampon Taxes? Empirical Evidence from New Jersey, 15 J. EMPIRICAL L. STUD. 620, 625-26 (2018).

${ }^{16}$ The Unequal Price of Periods, ACLU (2021), https://www.aclu.org/report/unequal-price-periods, [https://perma.cc/8PHR-J2QS]; Supplemental Nutrition Assistance Program (SNAP), USDA (2021), https://www.fns.usda.gov/snap/eligible-food-items [https://perma.cc/FE3J-XXQC].

${ }^{17}$ Va. Code $\S 22.1-6.1(2020)$.

${ }^{18}$ See, e.g., Johnson, et. al., supra note 7, at 255-56; Va. Code §22.1-6.1 (2020); Tenn. Code § 49-6-417 (2019).

${ }^{19}$ See Molly Secor-Turner, Andrea Huseth-Zosel \& Rachel Ostlund, Menstruation Experiences of Middle and High School Students in the Midwest: A Pilot Study, J. OF SCH. Nursing 1, 1-7 (2020).

${ }^{20}$ See Christopher A. Cotropia, Menstruation Management in United States Schools and Implications for Attendance, Academic Performance, and Health, 6 Women's Reprod. Health 289, 289-90, 304-05 (2019).
} 
a restroom, grants menstruators the autonomy similarly enjoyed by those who address their biological needs with already freely provided toilet paper or paper towels.

The legislation also addresses period poverty by providing MHPs for free to schoolaged menstruators. ${ }^{21}$ Making MHPs available for free at school addresses access issues for those who have difficulty affording these necessary and expensive products. ${ }^{22}$ And, if schools provide them in the restroom, access to MHPs is not limited by school nurses or other administrators.

\section{Limits to the Force of These Legal Changes}

On paper, eliminating the tampon tax and providing free MHPs in schools makes practical sense. These legal changes can "make[] a difference" via the law's coercive power to demand a particular action (i.e. remove the tampon tax and/or provide MHPs to students). ${ }^{23}$ The question becomes whether the force of law alone can achieve the menstrual movement's goals. Put another way, how far does the effect of law go in achieving menstrual equity and eliminating period poverty? As described in more detail below, the legal changes sought by the movement will push society closer to these goals. But the magnitude of change they directly achieve is likely quite small.

\section{A. Establishing Equity}

On their face, the operation of both proposed legal changes - repealing the tampon tax and providing free MHPs in school restrooms - should promote equity. By no longer collecting the tampon tax, state governments stop taxing a biological necessity. Research indicates that consumers bear the economic incidence of the current sales tax, meaning that repeal would result in realized savings. ${ }^{24}$ Similarly, by providing MHPs in school restrooms, free of charge, state governments can ensure that all students get all of the hygiene products they need while attending school. Further, the law's operation provides access in a very autonomous way - in the bathroom - allowing students to use MHPs without the embarrassment of having to self-identify, risk accidents, or ask administrators

\footnotetext{
${ }^{21}$ Editorial, Period Poverty in Public Schools: A Neglected Issue in Adolescent Health, 67 J. AdOLESCENT HEALTH 315 (2020)

${ }^{22}$ See Cotropia, supra note 20, at 290-92.

${ }^{23}$ See, e.g., Frederick Schauer, The Force of Law (2015).

${ }^{24}$ See Cotropia \& Rozema, supra note 15 , at 639.
} 
or teachers for products. By removing these burdens, menstruators may enjoy uninterrupted access to education, along with better hygiene and health. ${ }^{25}$

But practically, these legal changes may not have the full equalizing effect for which advocates hope. With regard to monetary discrimination based on menstrual need, there is still the "pink" tax - a misnomer referring to how MHPs are more expensive than comparable biologically male oriented products, even before the sales tax. ${ }^{26}$ In addition, eliminating the sales tax does not render the purchase and use of such goods less taboo.

The equalizing effect of providing MHPs in schools is also limited. Providing increased access without accompanying education and awareness may do little to address the stigma of menstruation. ${ }^{27}$ In fact, placing the goods in the bathroom could even entrench the stigma by pushing menstruation further out of sight.

None of the above means to suggest that these legal changes do nothing to address menstrual equity - only to recognize that the force of law faces limitations, in some instances significant ones, in effectuating menstrual justice.

\section{B. Increasing Access}

These proposed legal changes can also increase access to MHPs and, in turn, reduce period poverty. Legislation requiring provision of free MHPs in schools is the most direct remedy because it gives direct access to people who cannot afford them. Removing the sales tax reduces the cost of MHPs, indirectly increasing access by making them more affordable. Research also shows that when a tampon tax is repealed, MHP prices lower even further, in turn providing more access. ${ }^{28}$

But there are reasons to believe these benefits are overstated. With regard to MHPs in school, a major problem is that the legislation typically comes in the form of unfunded

\footnotetext{
${ }^{25}$ See Cotropia, supra note 20, at 291; Secor-Turner et al., supra note 19.

${ }^{26}$ See Megan Duesterhaus, Liz Grauerholz, Rebecca Weichsel \& Nicholas A. Guittar, The Cost of Doing Femininity: Gender Disparities in Pricing of Personal Care Products and Services, 28 GENDER Issues 175, 182-83 (2011).

${ }^{27}$ See Chris Bobel, Menstrual Pads Can't Fix Prejudice, N.Y. TimEs (Mar. 31, 2018), https://www.nytimes.com/2018/03/31/opinion/sunday/menstrual-periods-prejudice.html [https://perma.cc/L82L-AFEK].

${ }^{28}$ See Cotropia \& Rozema, supra note 15, at 633.
} 
mandates, meaning that school districts' budgets may limit the laws' practical effects. Given tight local budgets, there is a real possibility that MHPs in school legislation, even when passed, will be unfunded. This has been the experience in some early adopting states like New York and Illinois. ${ }^{29}$ Even if the mandates are initially funded, advocates fear that funding will not continue. ${ }^{30}$

Additionally, the cost savings from a tampon tax repeal may not be large enough to truly increase access. The projected yearly savings is $\$ 5.25$ dollars per consumer. ${ }^{31}$ These savings may buy one package of MHPs but not much more, making the increased access marginal.

Some advocates also warn that the goal of improving access requires a more direct approach, and efforts to repeal tampon taxes or require MHPs in public schools may divert resources from such a broad, direct approach. These critics argue that the legal changes decrease tax revenue, via the tampon tax repeal, which could be used to provide such direct relief ${ }^{32}$ or increase accessibility for all menstruators, meaning that some local funds are "wasted" on students not in period poverty, leaving less funds for those in real need.

Again, as with equity, these legal changes will increase some access to MHPs. The point is that even if these legal changes are fully enforced, the menstrual movement may not reach its goal of eliminating period poverty for everyone through the mere operation of law alone.

\section{Significant Expressive Benefits of These Legal Changes}

Even if the direct effects are somewhat muted, the force of law is not the only mechanism by which legal change becomes social change. Law is expressive-symbolic

\footnotetext{
${ }^{29}$ See Dusty Rhodes, Dispensing Dignity: IL Law Promised Free Supplies in Schools, NPR (Feb. 26, 2020), https://www.nprillinois.org/post/dispensing-dignity-il-law-promised-free-supplies-schools\#stream/ [https://perma.cc/K6NC-TBYA\#stream/0].

${ }^{30}$ See, e.g., Ernie Garcia, New Tampon Law May Cost Yonkers Up to \$200,000 Yearly, LOHUD (Aug. 16, 2018), https://www.lohud.com/story/news/local/westchester/yonkers/2018/08/16/ny-tampon-law-costyonkers/1006793002/ [https://perma.cc/FPT6-MHLT].

${ }^{31}$ See Cotropia \& Rozema, supra note 15 , at 626.

${ }^{32}$ Nicole Kaeding, Tampon Taxes: Do Feminine Hygiene Products Deserve a Sales Tax Exemption? TAx Found. (Apr. 2017), https://files.taxfoundation.org/20170425105103/Tax-Foundation-FF547.pdf [https://perma.cc/XXH3-8UPT].
} 
by stating what is legitimate or "right." 33 This expressive nature is a vehicle by which social norms are promoted and furthered, not through the law's enforcement, but through the information generated and conveyed via its passage and implementation and the societal coordination it facilitates. ${ }^{34}$ These expressive aspects of law may be the main benefit, and perhaps the more systemic one, to proposing and passing a tampon tax repeal or requiring MHPs to be distributed for free in schools. The process of advocating for, presenting, and eventually implementing these legal changes activates laws' symbolic, informational, and coordination benefits.

\section{A. Symbolic}

Legal changes focused on addressing menstrual equity and period poverty, even if not fully effective, have tremendous symbolic power because they communicate and legitimize these goals to society writ large. That menstruation-related issues garner the attention and, in some cases, action of government entities signals that the needs of menstruators are significant and real. This symbolic function can come from legislation and civil actions themselves, but also derives from the statements of purpose surrounding such legal proposals.

For example, legislation in Illinois regarding MHPs in school is entitled the "Learn with Dignity Act" and explains, in the text of the bill, that MHPs are a necessity, access to which is a serious need. ${ }^{35}$ Tampon tax repeal legislation proposed in Virginia is presented as "The Dignity Act." "36 Governor Cuomo framed New York's passage of MHPs in school legislation as "a critical step forward in ensuring every girl in New York has the same opportunities to grow into a confident, successful woman," and a way to "provid[e] all students with equal access to these products . . creating a strong, healthier New York for all." 37 The complaint in a Michigan class action, which was signed under penalty of perjury, filed with a state court, and made publicly available for all to see,

\footnotetext{
${ }^{33}$ See, e.g., Cass R. Sunstein, On the Expressive Function of Law, 144 U. PA. L. REv. 2021 (1996).

${ }^{34}$ See, e.g., Richard H. McAdams, The Expressive Powers of LAW: Theories ANd Limits (2015); see also Janice Nadler, Expressive Law, Social Norms, and Social Groups, 42 L. \& Soc. INQUiRY 60 (2017).

${ }^{35}$ H.B. $3215,100^{\text {th }}$ Gen. Assemb. (Ill. 2017).

${ }^{36}$ H.B. 1593, 2017 Reg. Sess. (Va. 2017).

${ }^{37}$ Governor Cuomo Reminds Schools of New Law Requiring School Districts to Provide Free Feminine Hygiene Products in Restrooms, GOVERNOR.NY.GOV (Sept. 10, 2018), https://www.governor.ny.gov/news/governor-cuomo-reminds-schools-new-law-requiring-school-districtsprovide-free-feminine-hygiene [https://perma.cc/J3FF-HEUR].
} 
explains that MHPs are a necessity and the tax unfairly targets those who menstruate. ${ }^{38}$ Each of these statements articulate the symbolism of their proposed legal changes.

\section{B. Informational}

There are significant informational benefits from the proposed legal changes. Each bill and lawsuit comes with testimony, discussion, and resulting news coverage detailing menstruation and the challenges it presents. Such information and public discourse prompts comments such as "I have never thought about that" or "I had no idea." The information produced by proposing legal change effectuates a fundamental goal of the movement - menstrual awareness. Simply presenting this legislation "open[s] up political dialogue on what is still considered a taboo subject." 39

And when these laws are passed (or court injunctions are issued), law's informational nature continues via the mechanics of implementation. Businesses must change their point-of-sale software to remove MHPs from the sales tax base, and school boards and administrators must face the practical considerations of obtaining, installing, and filling MHP dispensers. Through this process, more individuals learn about the inequities and access issues menstruators currently experience and do so at the direction of legitimizing governmental directives. "Once you educate people about it, I truly think they get it . . . [t]alking about the need and mobilizing to address the need is really easy to do and get excited about." 40

\section{Coordination}

These laws and lawsuits also facilitate further community coordination and engagement with the menstrual movement. By bringing period equity and poverty to light as well as detailing ways to address them, these sought-after legal changes sparked the creation of menstruation-related non-profits, MHP donation and collection drives, and

\footnotetext{
${ }^{38}$ See Complaint, Beggs v. Michigan, No. 20-000149-MT, at 1-5.

${ }^{39}$ Ali Dusinberre, Coronavirus Could Sideline Important Period Poverty Bill, The Boston Scope (April 28, 2020), https://thescopeboston.org/4012/news/coronavirus-could-sideline-important-period-poverty-bill/ [https://perma.cc/UA2N-V8X5].

${ }^{40}$ Leah Rodriguez, Georgia Will Give Free Pads and Tampons to Low-Income People, GLOBAL CITIZEN (Apr. 10, 2019), https://www.globalcitizen.org/en/content/georgia-period-products-low-income-budget/ [https://perma.cc/B8PJ-2VTE].
} 
other community action to effectuate the menstrual movements goals. ${ }^{41}$ Law in this area creates a focal point around which those sympathetic to the menstrual movement can rally, and an entry point for those who have never considered these issues before.

Community and school responses to the MHP access issues presented by COVID-19 are a great example of these legal changes' coordination benefits. Due to COVID-19, most schooling is remote, which prevents students from accessing MHP dispensers in schools, if there are any. Furthermore, shutdowns have caused many people to lose their jobs, increasing the number of people who are period poor. ${ }^{42}$ While the MHPs in school legislation does not provide a direct legal solution, these laws express a concern (period poverty) and a solution (provide MHPs for free) that define a common cause and response that school administrators, local governments, and those in the community can mimic. As a result, there are a number of examples of local communities and governments distributing MHPs to fill the need, particularly in states that have passed pertinent legislation, such as California and New York. ${ }^{43}$ While these laws do not mandate such distribution, they create clarity and direction for societal coordination and action to address the period poverty exacerbated by COVID-19.

\section{CONCLUSION}

This essay is less for those supportive of the menstrual movement's current legal agenda and more a response to those who question it. Both lawmakers and menstrual advocates have legitimate arguments as to how much the force of law can actually accomplish here. But such a focus on law's direct effects ignores the value of its expressive function, particularly in this context. Law's symbolism and informational and coordination functions assist the menstrual movement not only in removing a tax and putting more MHPs in schools, but also in achieving its overarching goal of menstrual

\footnotetext{
${ }^{41}$ See Megan McGibney, Ending Period Poverty Is Within Sight for These Young People, TeEN VoGuE (Jan. 13, 2021), https://www.teenvogue.com/story/ending-period-poverty [https://perma.cc/3R2D-8ZAJ].

42 See Marni Sommer, Let's Talk About Menstruation, ColumBIA News (Apr. 14, 2020), https://news.columbia.edu/news/period-menstruation-products-covid-19-shortage-women [https://perma.cc/BWV3-J4E4].

${ }^{43}$ See Chloe Atkins, Two NYC Students Push to Ensure Period Hygiene Products Are Given Out, NBC NEws (May 24, 2020), https:/www.nbcnews.com/news/us-news/two-nyc-students-push-ensure-period-hygieneproducts-are-given-n1213456 [https://perma.cc/ZPN2-D8LZ].
} 
awareness and acceptance. As many have pointed out, "policy is a must, but ... a change in attitude has to happen too, ${ }^{44}$ a change that law can help bring about.

${ }^{44}$ Alicia Napierkowski, Period Poverty Is Getting Worse During the Pandemic, TeEn Vogue (Oct. 7, 2020), https://www.teenvogue.com/story/period-poverty-getting-worse-during-the-pandemic

[https://perma.cc/7U5G-XVGS]. 